\title{
Comparison of Different Control Strategies of Multilevel Inverters Used to Fed a Dual Star Induction Machine
}

\author{
Kamal Himour $^{1 *}$, Abdelhalim Yahiaoui ${ }^{2}$, Koussaila Iffouzar ${ }^{3}$ \\ ${ }^{1}$ Department of Technology, Institute of Sciences, University Center of El Bayadh, BP 900, EL Bayadh 32000, Algeria \\ ${ }^{2}$ Laboratoire de Maitrise des Energies Renouvelables, Faculté de Technologie, Université de Bejaia, Bejaia 06000, Algeria \\ ${ }^{3}$ Ecole supérieure des Sciences Appliquées d'Alger, Département Second Cycle, Alger 16000, Algeria
}

Corresponding Author Email: himour.kamal@hotmail.fr

https://doi.org/10.18280/jesa.530411

Received: 4 May 2020

Accepted: 1 August 2020

\section{Keywords:}

dual star induction machine, multilevel inverters, pulse width modulation strategy, simplified space vector control strategy, random pulse width modulation strategy

\begin{abstract}
Multiphase machines have interesting advantages in terms of torque ripple and rotor losses which will be lower compared to three-phase machines. Thus, the power of these machines can be done with multilevel inverters that offer good quality energy. The work presented in this paper consists of an analysis of the effect of control techniques of multilevel inverters feeding a dual-star induction machine. The waveform of the output voltage of the inverters depends on the topology of the inverter and its control strategy. We will present a comparative simulation study between three control strategies (PWM, RPWM and simplified SVM) for a three-level diode clamped inverter that feds a dual-star induction machine. The results of simulations will be discussed.
\end{abstract}

\section{INTRODUCTION}

Recently, researchers are increasingly interested in multiphase machines, particular, the dual star induction machine. The latter has several advantages such as: reliability, minimization of torque pulsations, which allows the use of electronic components of reduced design power for frequencies of switching higher than with three-phase machines [1-5].

Indeed, the progress of digital electronics and the developments of power components allow today to develop a new structure of so-called multilevel converters. In the literature, several multilevel converter topologies have been proposed [6-8]. They mainly include, in a chronological order, the cascaded structure, the floating diode structure and the flying capacitors structure.

Among the multilevel structures, diode clamped structure is an interesting alternative to fed multiphase induction machines [9-12]. Indeed, their topology resulting from series associations of a large number of power components allows operations of high voltage while providing excellent waveforms.

The purpose of this work is to present a comparative simulation study between three control strategies (Pulse Width Modulation, Random PWM and simplified space vector modulation for a three-level diode clamped inverter that feds a dual-star induction machine.

For this, the first section will be devoted to the general study and modeling of dual star induction machine and the three levels Diode Clamped Inverter, the simulation study is performed under the Simulink environment of Matlab.

In the second section, we will present three different control strategies for the three level DCI, such as: pulse width modulation, random pulse width modulation and simplified space vector control strategy.
Finally, the last section will be devoted to numerical simulations as well as the interpretation of the results obtained. We will end with a general conclusion about the work done.

\section{SYSTEM'S MATHEMATICAL MODEL}

\subsection{Park model of dual star induction machine}

The DSIM consists of a stator bearing two identical threephase windings and offset by an electric angle $\alpha=30^{\circ}$ and a squirrel cage rotor.

Figure 1 shows the generalized model according to the (d, q) axis system.

\section{Electric equations:}

Then the final equations of the DSIM are:

$$
\begin{aligned}
& v_{s 1 d}=R_{s 1 d} i_{s 1 d}+\frac{d}{d t} \emptyset_{s 1 d}-\omega_{s} \emptyset_{s 1 q} \\
& v_{s 1 q}=R_{s 1} i_{s 1 q}+\frac{d}{d t} \emptyset_{s 1 q}+\omega_{s} \emptyset_{s 1 d} \\
& v_{s 2 d}=R_{s 2 d} i_{s 1 d}+\frac{d}{d t} \emptyset_{s 2 d}-\omega_{s} \emptyset_{s 2 q} \\
& v_{s 2 q}=R_{s 2} i_{s 2 q}+\frac{d}{d t} \emptyset_{s 2 q}+\omega_{s} \emptyset_{s 2 d} \\
& 0=R_{r} i_{r d}+\frac{d}{d t} \emptyset_{r d}-\left(\omega_{s}-\omega_{r}\right) \emptyset_{r q} \\
& \left(0=R_{r} i_{r q}+\frac{d}{d t} \emptyset_{r q}+\left(\omega_{s}-\omega_{r}\right) \emptyset_{r d}\right.
\end{aligned}
$$

Magnetic equations:

$$
\left[\begin{array}{c}
\emptyset_{s 1 d} \\
\emptyset_{s 2 d} \\
\emptyset_{r}
\end{array}\right]=\left[\begin{array}{ccc}
L_{s 1}+L_{m} & L_{m} & L_{m} \\
L_{m} & L_{s 2}+L_{m} & L_{m} \\
L_{m} & L_{m} & L_{r}+L_{m}
\end{array}\right]\left[\begin{array}{c}
i_{s 1 d} \\
i_{s 2 d} \\
i_{r}
\end{array}\right]
$$




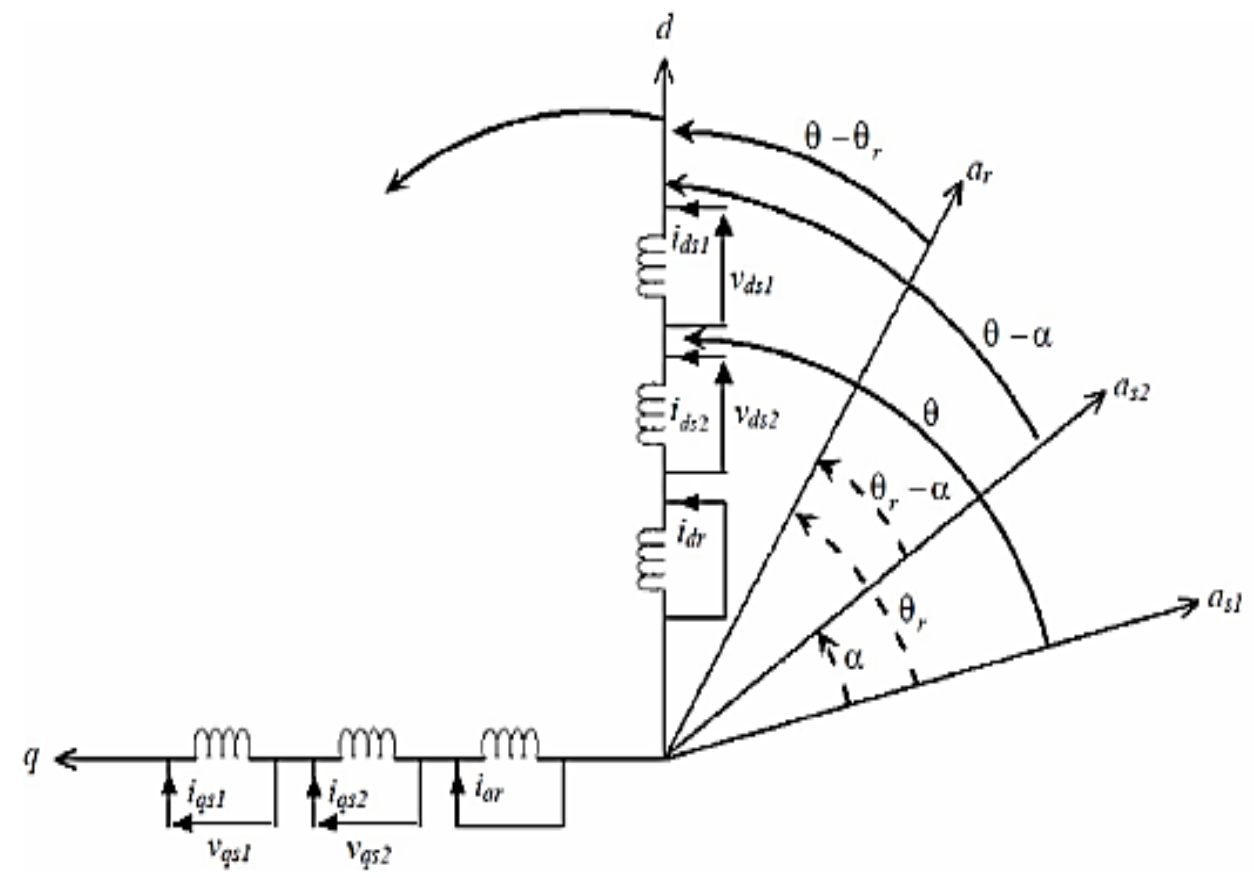

Figure 1. Schematic representation of the Park model of the DSIM

$\left[\begin{array}{c}\emptyset_{s 1 q} \\ \emptyset_{s 2 q} \\ \emptyset_{r}\end{array}\right]=\left[\begin{array}{ccc}L_{s 1}+L_{m} & L_{m} & L_{m} \\ L_{m} & L_{s 2}+L_{m} & L_{m} \\ L_{m} & L_{m} & L_{r}+L_{m}\end{array}\right]\left[\begin{array}{c}i_{s 1 q} \\ i_{s 2 q} \\ i_{r}\end{array}\right]$

With:

$\left(L_{s 1}+L_{m}\right),\left(L_{s 2}+L_{m}\right)$ : cyclical own inductance of star 1; $\left(L_{r}+L_{m}\right)$ : Cyclical own inductance of rotor;

$L_{m}=\left(\frac{3}{2}\right) L_{m s}=\left(\frac{3}{2}\right) L_{m r}=\left(\frac{3}{2}\right) L_{s r}:$ Mutual inductance between star 1 , star 2 and the rotor.

\section{Mechanical equation}

$$
\begin{aligned}
C_{e m}=P \frac{L_{m}}{L_{r}+L_{m}} & {\left[\emptyset_{r d}\left(i_{s 1 d}+i_{s 2 d}\right)-\emptyset_{r q}\left(i_{s 1 q}\right.\right.} \\
& \left.\left.+i_{s 2 q}\right)\right]
\end{aligned}
$$

The fundamental rotor rotation equation is described by the following relationships:

$$
\begin{gathered}
\frac{d}{d t} \Omega_{r}=\frac{1}{J}\left(C_{e m}-C_{r}-K_{f} \Omega_{r}\right) \\
\frac{d}{d t} \theta_{m}=\Omega_{r} \\
\omega_{r}=\frac{d}{d t} \theta_{r}
\end{gathered}
$$

\subsection{Modeling of three level DCI inverter}

The structure of this type of inverter is shown in Figure 2.

This inverter is composed of three arms, each arm having four bidirectional switches, made by the antiparallel setting of a transistor and a diode. To avoid short-circuiting the DC source in the input of the inverter or opening the AC load in the output, the four switches of one arm should not be closed or opened simultaneously. We suppose that the voltage Uc is divided into equality between the two capacitors: $\mathrm{U}_{\mathrm{c} 1}=\mathrm{U}_{\mathrm{c} 2}=$ $\mathrm{Uc} / 2$.

We introduce the connection function $S_{i s}$ of the switch which describes the state of every switch (1=closed, $0=$ opened).

With:

$\mathrm{i}$ : is the number of the leg of inverter,

$\mathrm{s}$ : is the number of the semiconductors

As indicated in Table 1, each leg of the inverter can have three possible switching states $\mathrm{P}, \mathrm{O}, \mathrm{N}$.

Table 1. States of one leg of 3 levels DCI

\begin{tabular}{llllcl}
\hline$S_{i 1}$ & $S_{i 2}$ & $S_{i 3}$ & $S_{i 4}$ & $V_{i 0}$ & State \\
\hline 0 & 0 & 1 & 1 & $-U_{c} / 2$ & $\mathrm{~N}$ \\
& & & & & $\mathrm{O}$ \\
0 & 1 & 1 & 0 & 0 & $\mathrm{P}$ \\
1 & 1 & 0 & 0 & $U_{c} / 2$ & \\
& & & & unknown & - \\
1 & 0 & 0 & 1 & r \\
\hline
\end{tabular}

The output voltages of a three level diode clamped inverter relatively to the middle point $\mathrm{O}$ with using the connection functions of the half-arm are expressed as follows:

$$
\begin{gathered}
{\left[\begin{array}{l}
V_{10} \\
V_{20} \\
V_{30}
\end{array}\right]=\frac{1}{3}\left[\begin{array}{ccc}
2 & -1 & -1 \\
-1 & 2 & -1 \\
-1 & -1 & 2
\end{array}\right] \cdot\left\{\left[\begin{array}{l}
S_{11}^{b} \\
S_{12}^{b} \\
S_{13}^{b}
\end{array}\right] \cdot U_{c 1}\right.} \\
\left.-\left[\begin{array}{c}
S_{10}^{b} \\
S_{20}^{b} \\
S_{30}^{b}
\end{array}\right] \cdot U_{c 2}\right\}
\end{gathered}
$$

With:

$$
S_{i 1}^{b}=S_{i 1} . S_{i 2}, S_{i 0}^{b}=S_{i 3} . S_{i 4}
$$




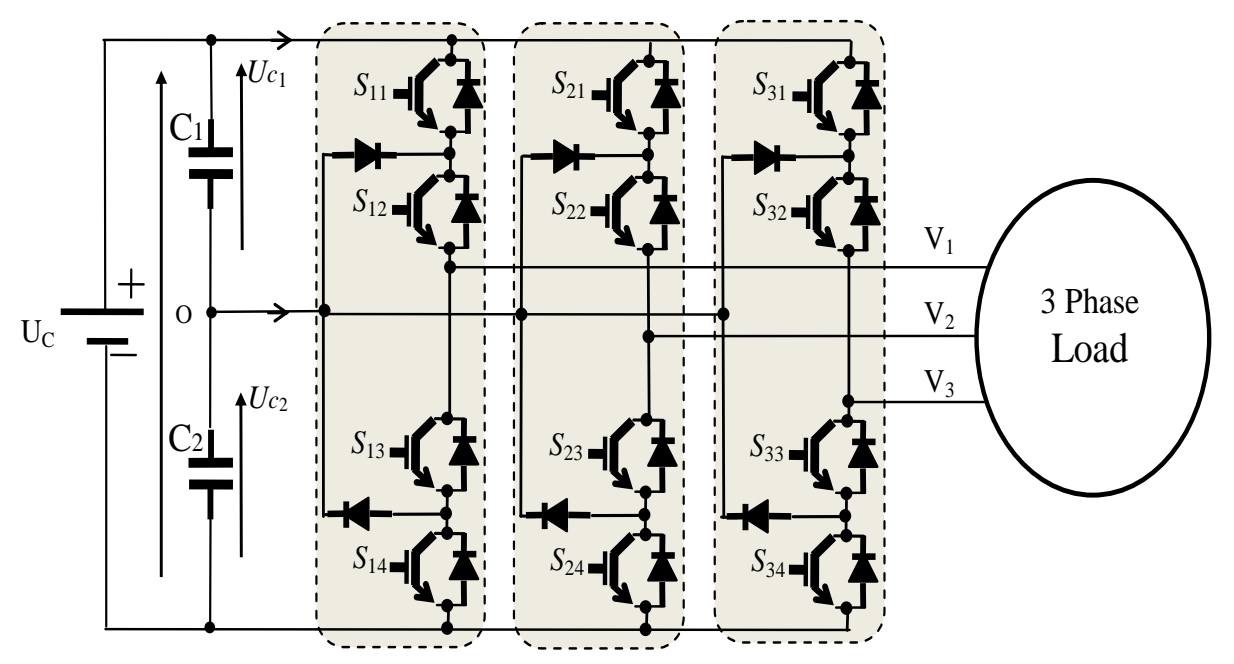

Figure 2. Three level diodes clamped inverter (DCI)

\section{CONTROL STRATEGIES}

\subsection{PWM control strategy}

The principle of this method is the comparison between a low frequency sinusoidal reference voltage and two higher frequency bipolar triangular carriers as shown in Figure 3. The switching times are determined by the points of intersection between the two carriers and the reference voltage.

The reference voltages used are expressed by:

$$
\begin{gathered}
\left\{\begin{array}{l}
V_{\text {ref1 }}=V_{m} \sin (\omega t) \\
V_{\text {ref2 }}=V_{m} \sin (\omega t-2 \pi / 3) \\
V_{\text {ref } 3}=V_{m} \sin (\omega t-4 \pi / 3)
\end{array}\right. \\
U_{p 1}= \begin{cases}V_{m}\left(\frac{4 t}{T_{p}}-1\right) & 0<t<\frac{T_{p}}{2} \\
V_{m}\left(3-\frac{4 t}{T_{p}}\right) & \frac{T_{p}}{2}<t<T_{p}\end{cases} \\
U_{p 2}=-U_{p 1}
\end{gathered}
$$

For this algorithm, two bipolar triangular carriers are shifted relative to each other by half a period. This algorithm can be summarized in the following two steps:

Step 1: Determination of intermediate voltages $\left(\mathrm{V}_{\mathrm{k} 1}, \mathrm{~V}_{\mathrm{k} 2}\right)$ :

$$
\left\{\begin{array}{c}
\left(\mathrm{V}_{\text {ref } \mathrm{k}}>\mathrm{U}_{\mathrm{p} 1}\right) \Rightarrow \mathrm{V}_{\mathrm{k} 1}=\mathrm{U}_{\mathrm{c}} \\
\left(\mathrm{V}_{\text {ref k }}<\mathrm{U}_{\mathrm{p} 1}\right) \Rightarrow \mathrm{V}_{\mathrm{k} 1}=0 \\
\left(\mathrm{~V}_{\text {ref k }}>\mathrm{U}_{\mathrm{p} 2}\right) \Rightarrow \mathrm{V}_{\mathrm{k} 2}=0 \\
\left(\mathrm{~V}_{\text {refk }}<\mathrm{U}_{\mathrm{p} 2}\right) \Rightarrow \mathrm{V}_{\mathrm{k} 1}=-\mathrm{U}_{\mathrm{c}}
\end{array} \quad \mathrm{k}=1,2,3\right.
$$

Step 2: Determination of the $\mathrm{V}_{\mathrm{km}}$ signal and the $\mathrm{B}_{\mathrm{ks}}$ control commands of the switches:

$$
\left\{\begin{array}{l}
V_{k m}=V_{k 1}+V_{k 2} \\
V_{k m}=U_{c} \Rightarrow B_{k 1}=1, B_{k 2}=1 \\
V_{k m}=-U_{c} \Rightarrow B_{k 1}=0, B_{k 2}=0 \\
V_{k m}=0 \Rightarrow B_{k 1}=1, B_{k 2}=0
\end{array} \quad k=1,2,3\right.
$$

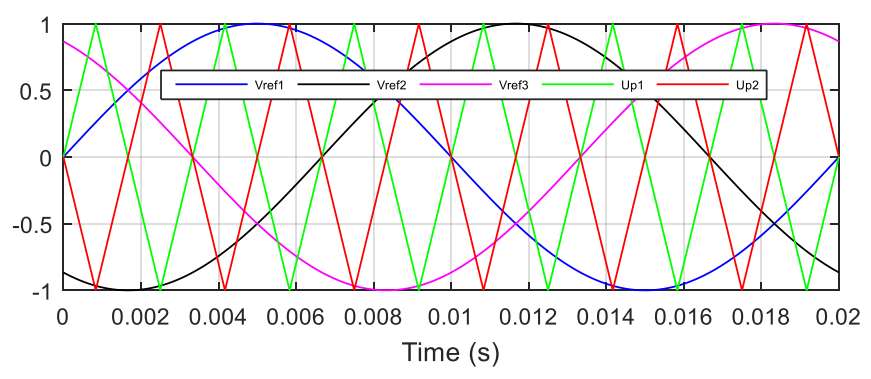

Figure 3. Reference voltages and two bipolar triangular carriers

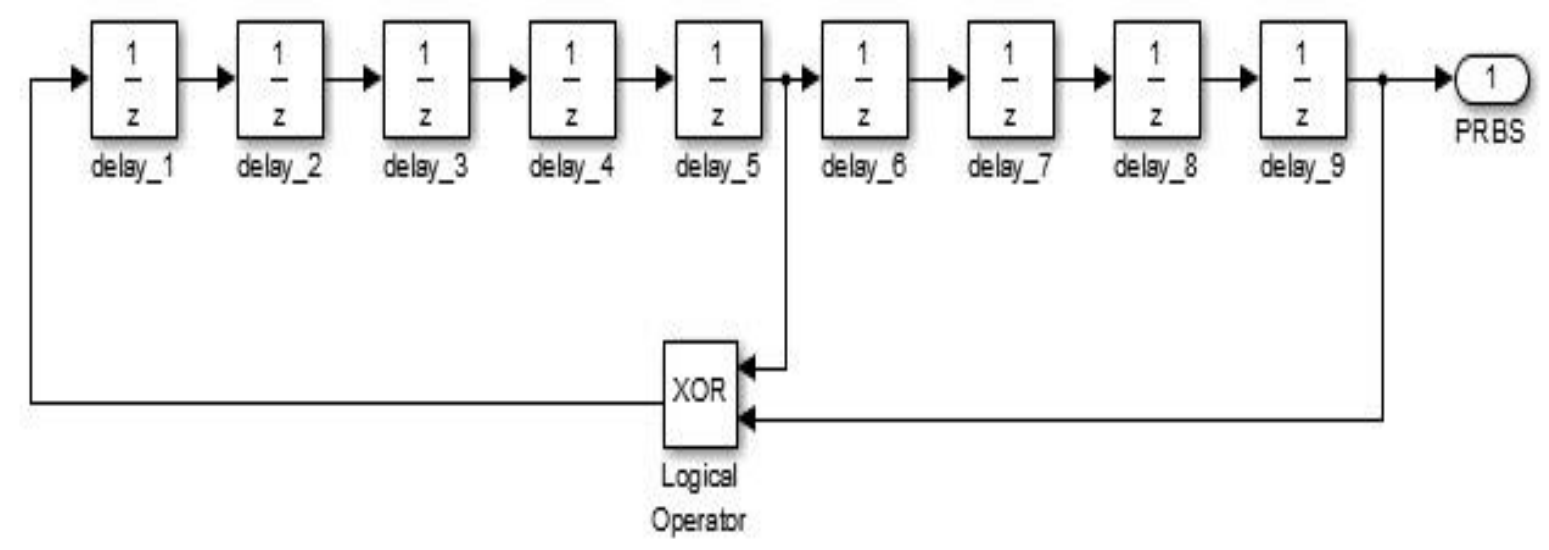

Figure 4. PRBS 9 bits scheme 


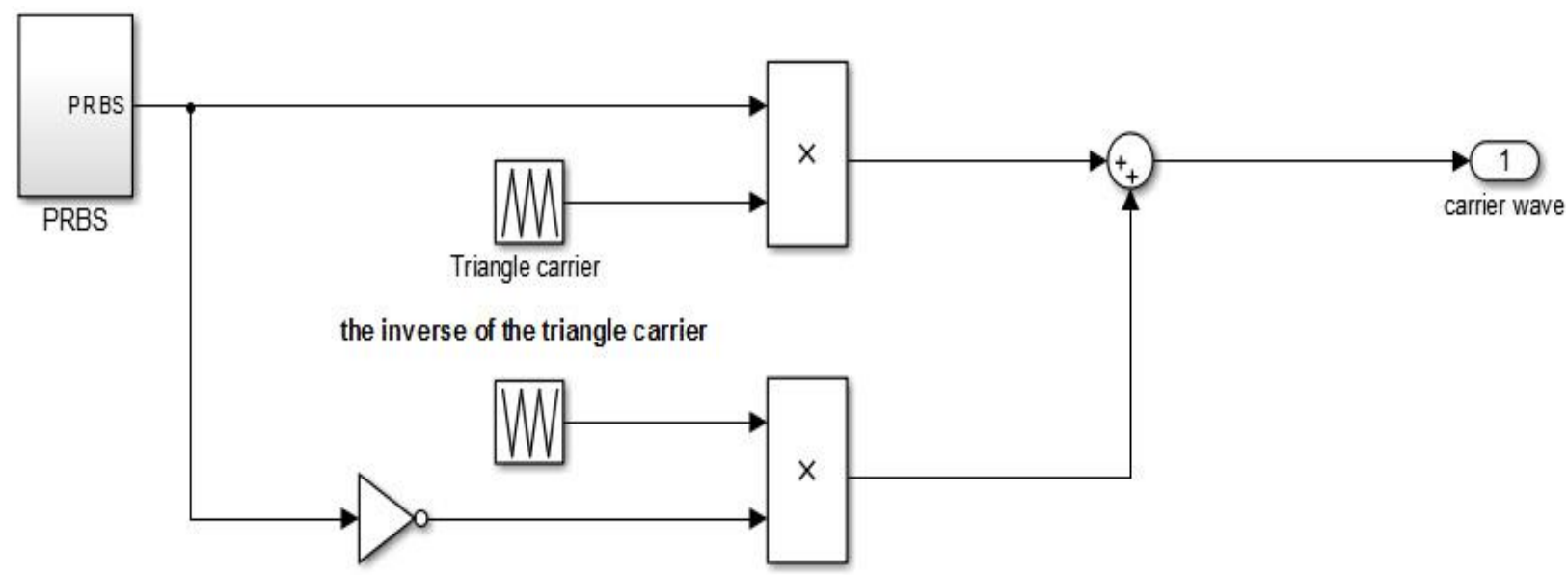

Figure 5. Carrier wave generation

\subsection{Random PWM control strategy}

The method is based on a random selection of the carrier frequency for each carrier period [13-18]. In this technique the randomization of frequency of carrier wave is by taking some times the carrier wave and the other times the inverse of carrier wave. So, for do this we work with PRBS (the random bits generator, Figure 4) which it generates random bites even 0 or 1 , we take the result of PRBS and multiple with the carrier wave and the inverse of PRBS multiple with the inverse of carrier wave and add the both results like it's been shown in Figure 4.

where, if the result of PRBS is one the inverse is 0 so the carrier wave is the same as classic PWM, but if PRBS generate 0 the carrier wave become the inverse of the carrier wave [1317] in this way we make a carrier signal (Figure 5) with random frequency which sometimes is bigger than the frequency of the same carrier wave and that's increase the quality of the fed wave because the THD is lower when the carrier frequency is higher.

By using the PRBS scheme, we can build two bipolar carrier random waves. Also, we can build the bloc of RPWM (Figure $6)$.

This algorithm consists of the same steps of the PWM algorithm.

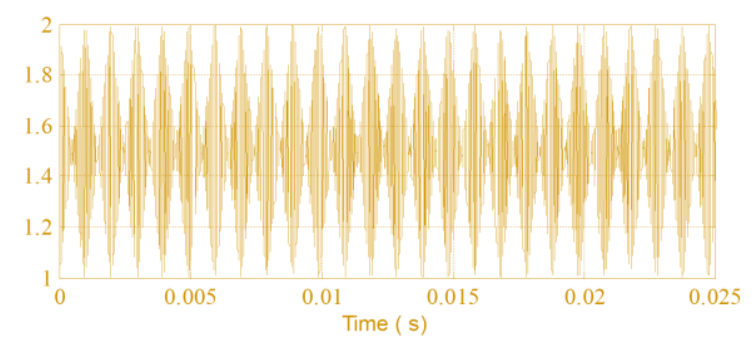

Figure 6. Carrier wave forme

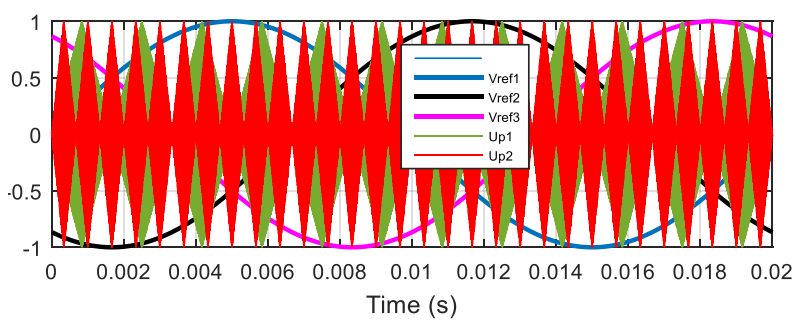

Figure 7. Reference voltages and two bipolar random carriers
Figure 7 shows the reference voltages and the two bipolar random carriers.

\subsection{Simplified space vector control strategy}

The output voltage vector is defined by:

$$
V_{s}=V_{10} e^{j 0}+V_{20} e^{-j 2 \pi / 3}+V_{30} e^{j 2 \pi / 3}=V_{d}+j V_{q}
$$

$\mathrm{V}_{\mathrm{d}}$ et $\mathrm{V}_{\mathrm{q}}$ : are the components of the vector $\mathrm{Vs}$ in the plane d-q.

This vector takes eighteen discrete positions in the plane d$\mathrm{q}$ according to the states of the inverter. These positions are shown in the vector diagram of the inverter (Figure 8).

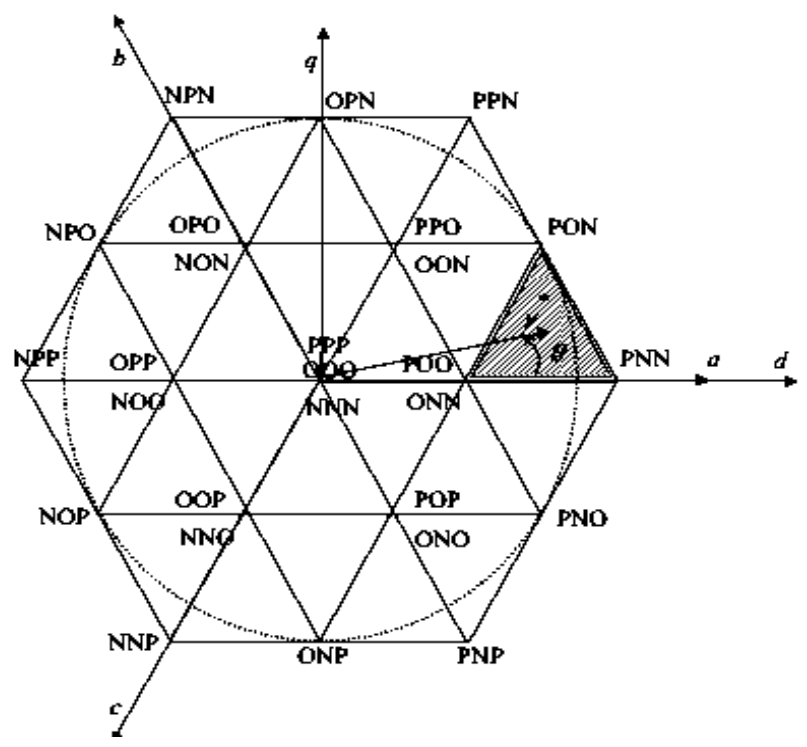

Figure 8. Vector diagram of three levels DCI

The discrete positions of the output voltage vector Vs divide the vector diagram into six triangular sectors, the vertices of these triangular sectors being the origin of the vector diagram and the apexes of the outer hexagon.

The vector diagram of the three-level inverter can be seen as consisting of six hexagons, each of which is the vector diagram of a two-level inverter. The centers of these six hexagons are the apexes of the inner hexagon of the vector diagram of the three-level as shown in Figure 9. This geometric decomposition of the vector diagram can be 
exploited to simplify the algorithm of the vector modulation of the three-level inverter with that of the vector modulation of the two-level inverter [18]. To achieve this goal, two steps must be taken:

According to the position of the vector reference voltage $V_{s}^{*}$, one of the six hexes indicated above is selected;

The origin of the vector $V_{s}^{*}$, is translated to the center of the hexagon selected in the first step.

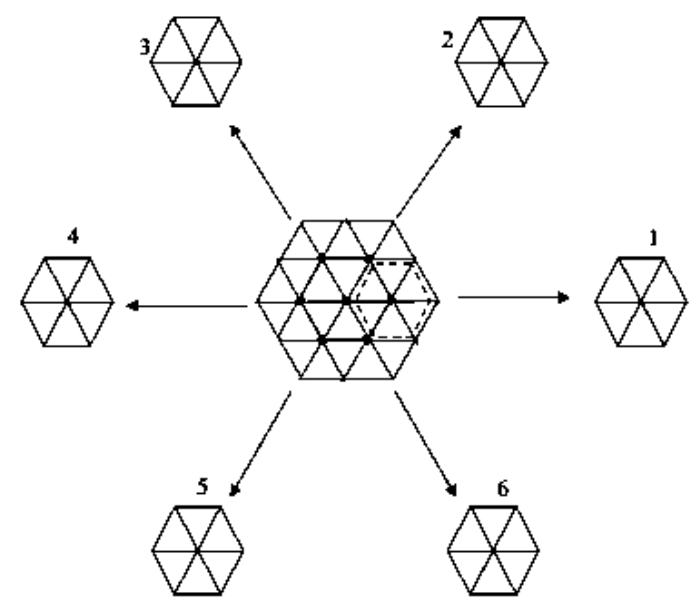

Figure 9. Decomposition of the vector diagram of the tree level DCI

\section{Algorithm of simplified SVM}

(1). Selecting a hexagon

Among the six hexagons composing the vector diagram of the three-level inverter, one selects the one that contains the vector reference voltage $V_{s}^{*}$, Each two adjacent hexagons overlap. Thus, each hexagon is indicated by a number $\mathrm{s}$ defined as follows:

$$
\text { s }=\left\{\begin{array}{c}
1 \text { si } \frac{-\pi}{3} \leq \theta \leq \frac{\pi}{3} \\
2 \text { si } \frac{\pi}{3} \leq \theta \leq \frac{\pi}{2} \\
3 \text { si } \frac{\pi}{2} \leq \theta \leq \frac{5 . \pi}{6} \\
4 \text { si } \frac{5 . \pi}{6} \leq \theta \leq \frac{7 . \pi}{6} \\
5 \text { si } \frac{7 . \pi}{6} \leq \theta \leq \frac{3 . \pi}{2} \\
6 \text { si } \frac{3 . \pi}{2} \leq \theta \leq \frac{11 . \pi}{6}
\end{array}\right.
$$

$\theta$ : is the angular position of the vector $V_{S}^{*}$, measured with respect to the axis $\mathrm{d}$.

(2). Change of origin of the reference voltage vector

The origin of the reference voltage vector $V_{S}^{*}$, is translated to the center of the selected hexagon. Figure 10 shows an example of translation in the case of a vector $V_{s}^{*}$, located in the second hex $(\mathrm{s}=2)$. The resulting vector after the translation is noted $V_{s}^{* \prime}$.

We consider the system of axes of d'-q 'whose origin $\mathrm{O}^{\prime}$ is positioned in the center of the selected hexagon (Figure 10). We have the vector relationship:

$$
V_{s}^{*}=V_{s}^{* \prime}+\overline{O O^{\prime}}
$$

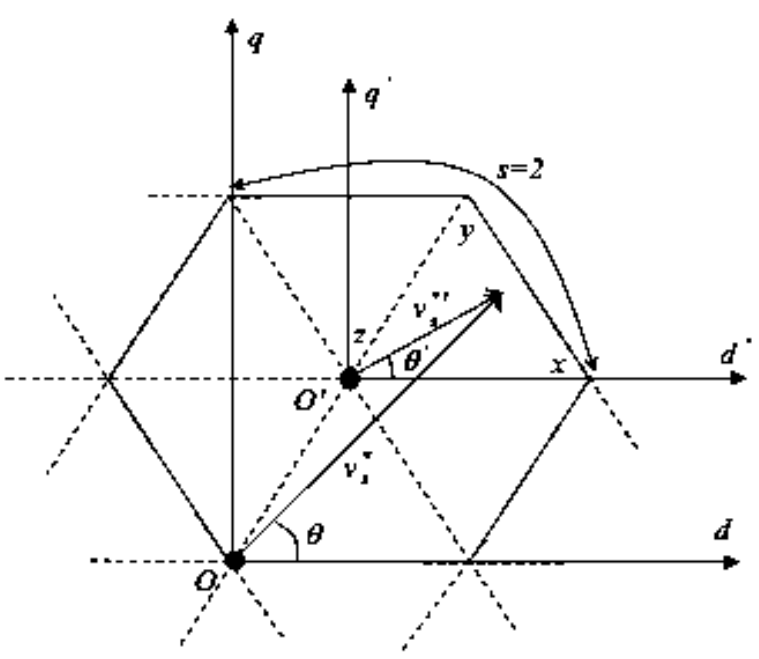

Figure 10. Change of origin of the reference voltage vector

The projections of this equation on the axes $d$ and q make it possible to express the components $V_{d}^{* \prime}$ and $V_{q}^{* \prime}$ of the vector $V_{s}^{* \prime}$ in the axis system of d-q' in function of the components $V_{d}^{*}$ and $V_{q}^{*}$ of the vector $V_{s}^{*}$ in the axis system dq.

Table 2 summarizes the expressions of the components $V_{d}^{* \prime}$ and $V_{q}^{* \prime}$ as a function of the components $V_{d}^{*}$ and $V_{q}^{*}$ for the six hexes (in relative quantities).

Table 2. Components $V_{d}^{* \prime}$ and $V_{q}^{* \prime}$

\begin{tabular}{ccc}
\hline Number of hexagons & $\mathbf{V}_{\mathbf{d}}{ }^{*}$, & $\mathbf{V}_{\mathbf{q}}{ }^{*}$, \\
\hline 1 & $\mathbf{V}_{\mathbf{d}}^{*}-\mathbf{1} / \mathbf{2}$ & $\mathbf{V}_{\mathbf{q}}^{*}$ \\
2 & $\mathbf{V}_{\mathbf{d}}^{*}-\mathbf{1} / \mathbf{4}$ & $\mathbf{V}_{\mathbf{q}}^{*}-\sqrt{\mathbf{3}} \mathbf{4}$ \\
3 & $\mathbf{V}_{\mathbf{d}}^{*}+\mathbf{1} / \mathbf{4}$ & $\mathbf{V}_{\mathbf{q}}^{*}-\sqrt{\mathbf{3}} / \mathbf{4}$ \\
4 & $\mathbf{V}_{\mathbf{d}}^{*}+\mathbf{1} / \mathbf{2}$ & $\mathbf{V}_{\mathbf{q}}^{*}$ \\
5 & $\mathbf{V}_{\mathbf{d}}^{*}+\mathbf{1} / \mathbf{4}$ & $\mathbf{V}_{\mathbf{q}}^{*}+\sqrt{\mathbf{3}} / \mathbf{4}$ \\
6 & $\mathbf{V}_{\mathbf{d}}^{*}-\mathbf{1} / \mathbf{4}$ & $\mathbf{V}_{\mathbf{q}}^{*}+\sqrt{\mathbf{3}} / \mathbf{4}$ \\
\hline
\end{tabular}

From the components $V_{d}^{* \prime}$ and $V_{q}^{* \prime}$, we deduce the angular position $\theta$ 'of the vector $V_{s}^{* \prime}$ with respect to the axis $\mathrm{d}$.

$$
\theta^{\prime}=\operatorname{arctg}\left(\mathrm{V}_{\mathrm{q}}^{* \prime} / \mathrm{V}_{\mathrm{d}}^{* \prime}\right)
$$

(3). Inverter state sequence

After selecting a hex and changing the origin of the reference voltage vector, the vector diagram of a two-level inverter, is obtained. Consequently, the determination of the sequence of states, and XYZ used to generate the output voltages, as well as their duration of application, is done in the same way as for the case of the vector modulation applied to the inverter with two levels. The relative times of the states, and XYZ over the sampling period are given by:

$$
\begin{gathered}
d_{x}=m^{\prime} \cdot \sin \left(\frac{\pi}{3}-\alpha\right) \\
d_{y}=m^{\prime} \cdot \sin (\alpha) \\
d_{z}=1-d_{x}-d_{y}
\end{gathered}
$$

$\alpha^{\prime}=\theta^{\prime}[\pi / 3]$ : it is the angular position of the vector $\mathrm{V}_{\mathrm{s}}^{* \prime}$, within the sectors of the selected hexagon.

$\mathrm{m}^{\prime}$ : This is the modulation rate relative to the vector $\mathrm{V}_{\mathrm{s}}^{* \prime}$ : 


$$
\mathrm{V}_{\mathrm{s}}^{* \prime}=\mathrm{m}^{\prime} \cdot \mathrm{V}_{\max }^{\prime} \cdot \mathrm{e}^{\mathrm{i} \theta^{\prime}}
$$

$\mathrm{V}_{\text {max }}^{\prime}$ : This is the maximum possible amplitude of the vector $\mathrm{V}_{\mathrm{S}}^{* \prime}$, inside the selected hexagon.

To express the modulation rate as a function of the modulation rate $\mathrm{m}$ linked to the reference vector $\mathrm{V}_{\mathrm{s}}^{*}$, we make the projection of Eq. (22) on the axis d, which gives, in relative quantities:

$$
\mathrm{m}^{\prime} \cdot \sqrt{\frac{3}{2}} \cdot \cos (\theta)=\mathrm{m}^{\prime} \cdot \sqrt{\frac{3}{2}} \cdot \frac{1}{2} \cdot \cos \left(\theta^{\prime}\right)+\Delta \mathrm{x}
$$

We deduce the expression of $\mathrm{m}$ 'as a function of $\mathrm{m}$ :

$$
\mathrm{m}^{\prime}=2 \cdot \mathrm{m} \cdot \frac{\csc (\theta)}{\csc \left(\theta^{\prime}\right)}-\frac{4 \cdot \Delta \mathrm{x}}{\sqrt{3} \cdot \cos \left(\theta^{\prime}\right)}
$$

Note that $\Delta \mathrm{x}$ is the projection of the vector $\overline{O O^{\prime}}$ on the axis of. It depends on the selected hex. His expression is:

$$
\Delta x^{\prime}=\left\{\begin{array}{l}
\frac{1}{2} \text { si } S=1 \\
\frac{1}{4} \text { si } S=2 \text { ou } S=6 \\
\frac{-1}{4} \text { si } S=3 \text { ou } S=5 \\
\frac{-1}{2} \text { si } S=4
\end{array}\right.
$$

\section{MODELING RESULTS}

In this section, the modeling results are obtained using Matlab Simulink. The switching frequency of the carriers is $1021 \mathrm{~Hz}$ and the DC voltage is $200 \mathrm{~V}$. Figures 11-14 show that the waveform of the voltage generated by the inverter has a better spectral quality with the SVM technique compared to the RPWM technique.

Figure 15 show that the torque ripples of the DSIM are reduced in case of RPWM and PWM control strategies compared to simplified space vector modulation strategy.

As shown in Figures 16 and 17, the amplitude of the stator current of the star 1 of the machine for the case of the RPWM and PWM strategy is lower than that obtained for the case of SSVM strategy.

The Table 3 below summarizes the different simulation results obtained for the three control strategies namely RPWM, SSVM and PWM.

Table 3. SVM, RPWM and PWM comparison

\begin{tabular}{cccc}
\hline & SVM & RPWM & PWM \\
\hline Voltage fundamental amplitude & 246.4 & 195.1 & 195.2 \\
Va1(V) & & & \\
Voltage THD \% & 21.39 & 40.7 & 40.71 \\
Current fundamental amplitude Ia1 & 15.93 & 12.89 & 12.89 \\
(A) & & & \\
Current Ia1 THD \% & 4.36 & 2.09 & 2.09 \\
Current fundamental amplitude Ia2 & 15.62 & 12.50 & 12.5 \\
(A) & & & \\
Current Ia2 THD \% & 4.08 & 2.06 & 2.061 \\
$\Delta$ Cem & 3 & 1.4 & 1.4 \\
\hline
\end{tabular}

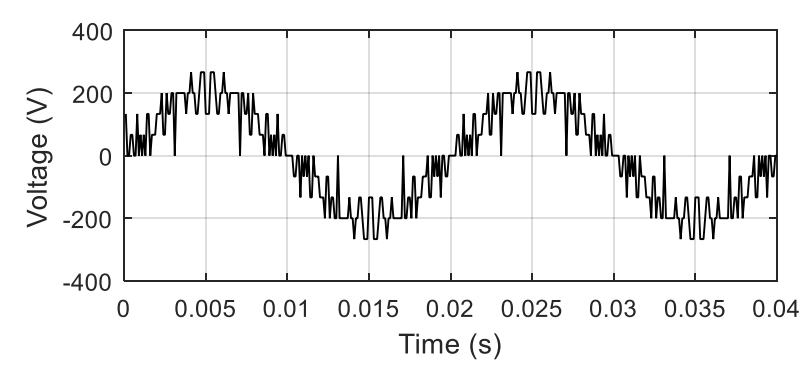

Figure 11. Stator voltage Vas1 with the RPWM strategy

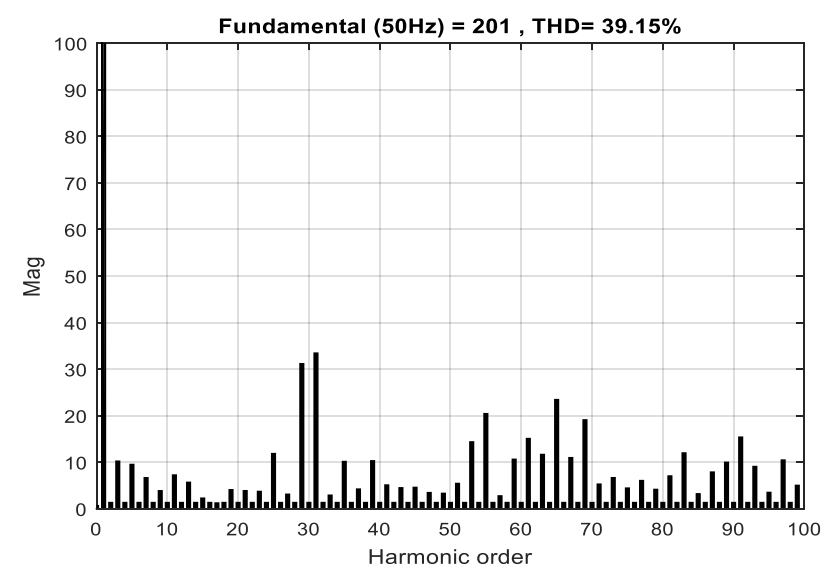

Figure 12. Harmonic analysis of Stator voltage Vas1 with the RPWM strategy

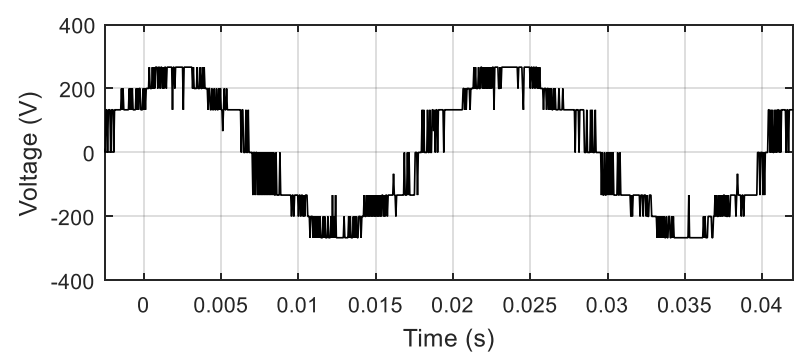

Figure 13. Stator voltage Vas1 with the SSVM strategy

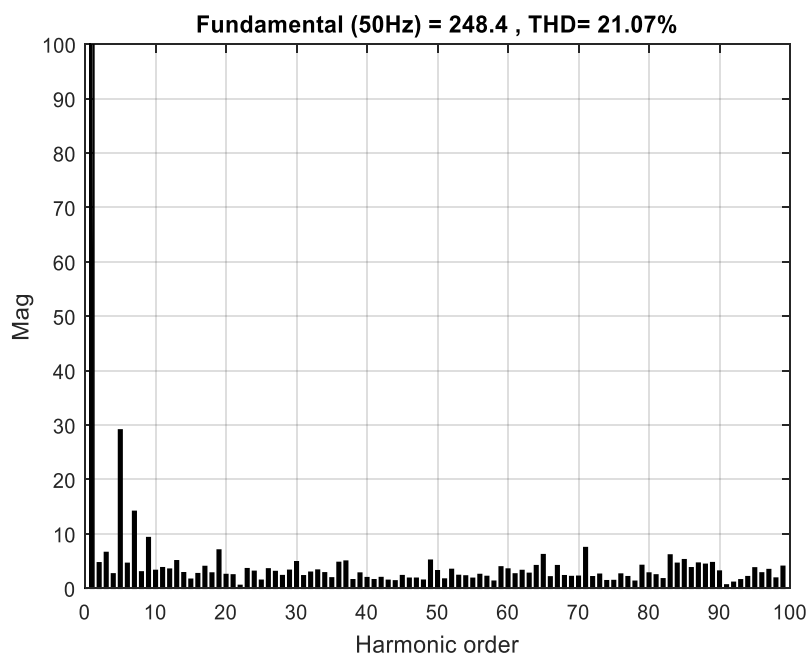

Figure 14. Harmonic analysis of Stator voltage Vas1 with the SSVM strategy 


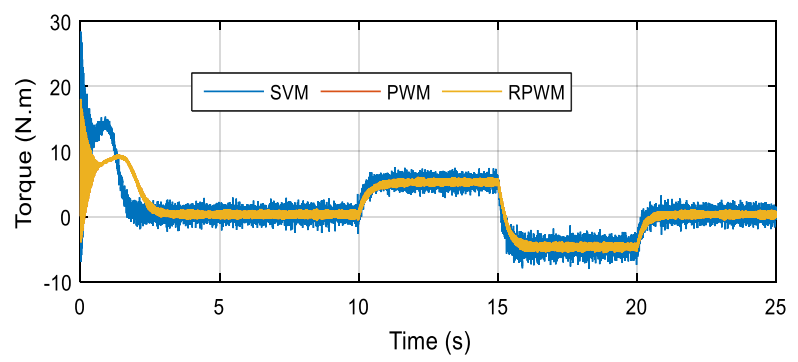

Figure 15. DSIM torque with different strategies

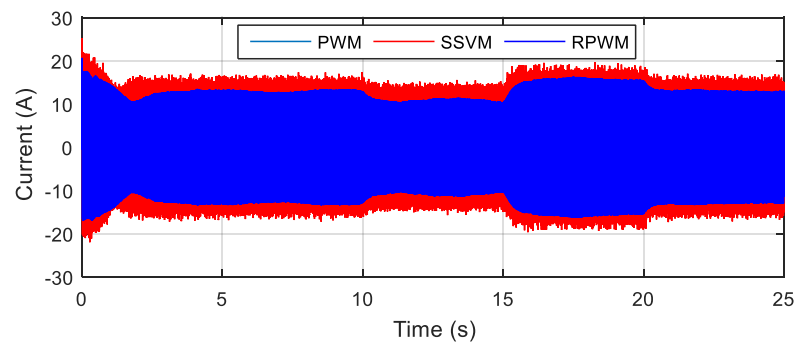

Figure 16. DSIM current phase 1 of star 1 with different strategies

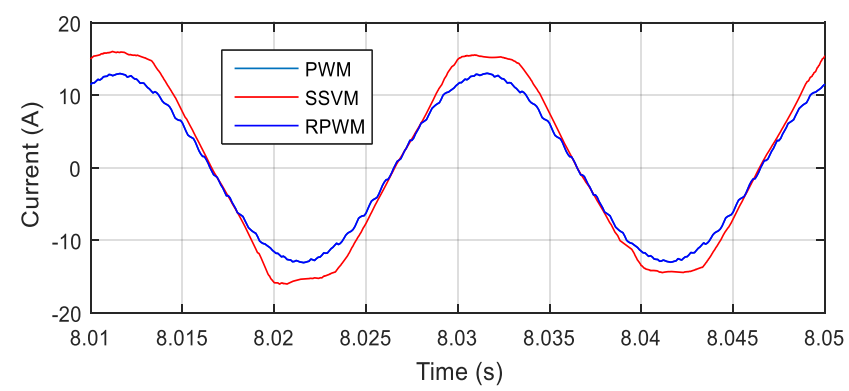

Figure 17. Zoom of DSIM current phase1 of star 1 with different strategies

\section{CONCLUSION}

In this article, a comparison between three control strategies of a three-level DCI inverter used to fed a dual-star inductions motor is presented. The simulation of the combination three levels DCI inverter- DSIM is done in the Simulink environment of Matlab. The results of this simulation showed the advantage of the simplified SVM technique in improving the quality of the motor supply voltage however the other two techniques (PWM and RPWM) gave ripples in the torque of the machine inferior to these ripples compared to the case of the simplified SVM.

\section{REFERENCES}

[1] Levi, E., Bojoi, R., Profumo, F., Toliyat, H.A., Williamson, S. (2007). Multiphase induction motor drives - A technology status review. IET Electric Power Applications, 1(4): 489-516. https://doi.org/10.1049/ietepa:20060342

[2] Amimmeur, H., Aouzellag, D., Abdessemed, R., Ghedamsi, K. (2012). Sliding mode control of a dualstator induction generator for wind energy conversion systems. International Journal of Electrical Power \& Energy Systems, 42(1): 60-70. https://doi.org/10.1016/j.ijepes.2012.03.024

[3] Singh, G.K. (2020). Multi-phase induction machine drive research-A survey. Electric Power Systems Research, 61: 139-147. https://doi.org/10.1016/S0378-7796(02)00007$\mathrm{X}$

[4] Yazidi, A., Pantea, A., Taherzahed, M., Carriere, S., Betin, F., Henao, H., Capolino, G.A. (2016). Six-phase induction machine model for fault simulation and control purposes using the circuit-oriented approach. IEEE Transactions on Industrial Electronics, 63(1): 494-503. https://doi.org/10.1109/TIE.2015.2493727

[5] Ion, B., Syed, A.N. (2010). The Induction Machines Design Handbook, Second Edition. Taylor \& Francis Group, USA.

[6] Benyettou, L., Tebbakh, M. (2018). Comparison performance five level and seven-level cascade h-bridge multilevel inverter of total harmonic distortion (THD). Modelling, Mesurment and Control A, 91(4): 157-167. https://doi.org/10.18280/mmc_a.910401

[7] Abdelghani, A.B., Martins, C.A., Roboam, X., Meynard, T.A. (2002). Use of extra degrees of freedom in multilevel drives. IEEE Trans. Ind. Electron., 49(5): 965977. https://doi.org/10.1109/TIE.2002.803183

[8] Franquelo, L.G. (2008). The age of multilevel converters arrives. IEEE Industrial Electronics Magazine, 2(2): 2839. https://doi.org/10.1109/MIE.2008.923519

[9] Colak, I., Kabalci, E., Bayindir, R. (2011). Review of multilevel voltage source inverter topologies and control schemes. Energy Convers Manage, 52(5): 1114-1128. https://doi.org/10.1016/j.enconman.2010.09.006

[10] Rodríguez, J., Sheng, L., Peng, J. (2002). Multilevel inverters: A survey of topologies, controls and applications. IEEE Trans. Industrial Electronics, 49(4): 724-738. https://doi.org/10.1109/TIE.2002.801052

[11] Monmasson, E. (2013). Power Electronic Converters: PWM Strategies and Current Control Techniques. Eric Monmasson (Editor). ISBN: 978-1-118-62284-1, WileyISTE.

[12] Tolbert, L.M., Peng, F.Z., Habetler, T.G. (2000). Multilevel PWM methods at low modulation indices. IEEE Transactions on Power Electronics, 15(4): 719-725. https://doi.org/10.1109/63.849042

[13] Jadeja, R., Ved, A., Chauhan, S. (2015). An investigation on the performance of random PWM controlled converters. Engineering, Technology \& Applied Science Research, 5(6): 876-884. https://doi.org/10.5281/zenodo.35430

[14] Kim, K.S., Jung, Y.G., Lim, Y.C. (2009). A new hybrid random PWM scheme. IEEE Transactions on Power Electronics, 24(1): 192-200. https://doi.org/10.1109/TPEL.2008.2006613

[15] Lim, Y.C. (2004). A new random PWM (SRP-PWM) technique for decreasing acoustic noise radiated from V/F controlled motor drives. 30th Annual Conference of IEEE Industrial Electronics Society, pp. 832-837. https://doi.org/10.1109/IECON.2004.1433423

[16] Shyu, J.L., Liang, T.J., Chen, J.F. (2001). Digitallycontrolled PWM inverter modulated by multi-random technique with fixed switching frequency. IEE Proceedings Electric Power Applications, 148(1): 62-68. https://doi.org/10.1049/ip-epa:20010102

[17] Leong, P.F. (2005). Random pulse-width modulated 
neutral-point-clamped inverter with reduced commonmode switching. International Conference on Power Electronics and Drives Systems, pp. 1435-1440.

[18] Lalili, D., Berkouk, E.M., Boudjema, F., Lourci, N.,
Taleb, T., Petzold, J. (2007). Simplified space vector PWM algorithm for three-level inverter with neutral point potential control. The Mediterranean Journal of Measurement and Control, 3(1): 30-39. 